\title{
Reliability and Validity Study for the Coloured Progressive Matrices Test between the Ages of 3-9 for Determining Gifted Children in the Pre-School Period
}

\author{
Ahmet Bildiren \\ Correspondence: Ahmet Bildiren, Assist. Prof. Dr., Special Education, Adnan Menderes University, Aydın, Turkey.
}

Received: August 15, 2017

doi:10.11114/jets.v5i11.2599
Online Published: September 21, 2017

URL: https://doi.org/10.11114/jets.v5i11.2599

\begin{abstract}
The objective of the study was to test the Coloured Progressive Matrices Test with regard to reliability and validity for the 3-9 age sample group because of the lack of diagnostic tools for the pre-school period. The sample group of the study was comprised of a total of 925 children with 433 girls (46.8\%) and 492 boys (53.2\%). Coloured Progressive Matrices Test reliability was analyzed by way of two split-half reliability and test-re-test reliability using Kuder Richardson-20 (KR-20) and Spearman-Brown Formula. The level of relationship between Coloured Progressive Matrices Test and Bender-Gestalt Visual Motor Perception Test and TONI-3 tests was determined via Pearson Product Moment formula for validity analyses. Afterwards, the age norms were determined as percentile values in accordance with the ages. The results obtained from the study provided psychometric data indicating that the Coloured Progressive Matrices Test is suited for the use by researchers.
\end{abstract}

Keywords: gifted children, raven's coloured progressive matrices test

\section{Introduction}

Determining gifted children and taking them onto early education has gained importance with the increasing value given to education during the early childhood period (Burns, Matthews, \& Mason, 1990; Burns \& Tunnard, 1991; Louis, Lewis \& Feiring 1991; Parkinson, 1990; Pfeiffer, 2002; Pfeiffer \& Jarosewich, 2003; Pfeiffer \& Petscher, 2008; Robinson \& Weimert, 1990; Rogers \& Silverman, 1988; Sankar-DeLeeuw, 2002; Shaklee \& Hansford, 1992). This importance has brought along with it the question as to how diagnosis will be carried out during the early childhood period.

Suggested application directives support the use of multi-criteria use for evaluating gifted and early childhood special education (Akarsu, 2001; Karnes, Shaunessy, \& Bisland, 2004; NAGC-CEC, 2006 Sandall, Hemmeter, Smith, \& McLean, 2005). The use of formal and informal evaluations together is advocated especially for diagnosis. Formal evaluation covers norm reference tests with completed standardization. Whereas those who carry out the informal evaluation are teachers who train and diagnose the children along with the families of pre-school children contribute to the process.

The most effective application in the diagnosis of gifted children is comprised of 3 stages in which formal and informal evaluation tools are used together. These are; candidacy stage, diagnosis stage and selection-placement stage (Johnsen, 2009). Using the information acquired in each stage, it is examined whether the child has the sufficient criteria to pass on to the next stage.

Children are accepted either individually or in small groups in order to evaluate their tendencies and cognitive skills during the diagnosis stage which is the second stage after the candidacy stage (Johnsen, 2009). Children can be evaluated at any age, however Silverman (2009) suggested the evaluation of children between the ages of 5 and 8 Because Silverman (2009) argued that it is possible for a 9 year old child to get a maximum score from the cognitive skill test.

Methods that are most frequently used for evaluating intelligence in Europe and America for children between the ages of 4-5 are, Kaufman Brief Intelligence Test $2^{\text {nd }}$ Publication (KBIT-2), Weschler Pre-School and Primary School Scale of Intelligence $3^{\text {rd }}$ Publication (WPPSI-III), Stanford-Binet Intelligence Scale $5^{\text {th }}$ Publication (SB5), Otis-Lennon School Ability Test (OLSAT), Naglieri Nonverbal Ability Test (NNAT) and Coloured Progressive Matrices (CPM) Test (Burns \& O’leary, 2004; Castellano, 2002; Lohman, Korb, \& Lakin, 2008; Özgüven, 2000; Öner, 1998; Raven, Raven \& Court, 1998). 
Second stage objective measurement tools are required in Turkey. None of the aforementioned scales used for diagnosing gifted children during the pre-school period can be used in Turkey since no study has been carried out on a wide sample group. The only study carried out for these scales was the doctorate thesis by Bildiren, Kargin and Korkmaz (2017) for Coloured Progressive Matrices towards children between the ages of 4-6. The Basic Skill Test (5-7), Goodenough-Harris Draw-a-Person test, Peadody Picture Vocabulary Test and the Bender Visual Perception test (Öner, 1998; Özgüven, 2000) are used in Turkey for the pre-school period. However, the adaptation study for majority of these tests were carried out during the 70's after which no revision study has been carried out. Determining the values from the norm groups is an important stage of test standardization. The test scores obtained from the application are evaluated in accordance with the norms that reflect group acquisition. One of the important attributes of norms is that they are relative with respect to time and space (Öner, 1998). The fact that almost 40 years have passed since the adaptation study of the tests used result in doubts regarding the reliability of the test values.

An increase in the number of pre-school diagnostic tools shall contribute to increasing the quality of educational evaluation and diagnosis processes. In this scope, various different evaluation tools are required. However, children from different genders, ethnic roots and socioeconomic infrastructures should all be evaluated objectively during diagnosis. Hence, each step of diagnosis processes should be carefully reviewed to ensure that a just approach is sustained towards each of the different sub-groups (Moon \& Rosselli, 2002). It can be stated that using tests that are independent of culture and language will tolerate such disadvantages (Kirschbaum, 1998; Lohman, Korb, \& Lakin 2008; Nagleri and Ford, 2005).

The Coloured Progressive Matrices test (CPM) and Naglieri Nonverbal Ability Test (NNAT) (Burns \& O'leary, 2004; Castellano, 2002; Lohman et.al., 2008; Raven et.al., 1998; Sattler, 2001) are among the first that come to mind among tests that are independent of culture and language. Lohman et. al. (2008) stated that Coloured Progressive Matrices test and Naglieri Nonverbal Ability Test are used frequently for determining gifted children with different languages during the pre-school period. Again, Lohman et. al. (2008) argue that tests such as CPM, NNAT which are not based on language should be used for measuring the skills in a just manner for cases when the children are not fluent in the language of the country he/she lives in. Even though it is stated that CPM may result in high test scores and inconsistent placements due to the insufficient norms in 1970 (Lohman et.al., 2008), it has been determined that CPM diagnoses more children with ethnic differences suited for programs for gifted children in comparison with NNAT, that children learn something from the previous question during the CPM test and that it may sometimes be more effective than NNAT in diagnosing minority students since it carries a continuity due to its nature (Lewis, DeCamp-Fritson, Ramage, McFarland \& Archwamety, 2007).

The Coloured Progressive Matrices test (Cotton et.al., 2005) used frequently for gifted education among small children in England, France, Canada, Italy, Hong Kong, Germany, Australia and many other countries can easily be applied on children with different gender, ethnic roots and socioeconomic infrastructure since it is independent of culture and language (Raven et. al., 1998). The Coloured progressive matrices test tests the problem solving skills of individuals without the use of language openly thereby measuring a special component of intelligence related behavior. Those who take the test have to employ different and complex reasoning strategies for solving this test with an abstract and formal content. Problem solving has been selected as the fundamental cognitive skill used in the coloured progressive matrices test (Raven et. al., 1998).

The insufficiency of diagnostic tools for the pre-school period makes up the leading motive for the study. Hence, reliability, validity and norm studies of the Coloured Progressive Matrices Test have been carried out for the 3-9 age sample group. It is thought that the study will contribute to the requirement in this field.

\section{Method}

\subsection{Participants}

The sample group of the study was comprised of a total of 925 children with 433 girls (46.8\%) and 492 boys (53.2\%). The ages of the children vary between 3 and 9. Socioeconomic layer which is thought to be an important indicator of intelligence was taken into consideration during the determination stage for the schools to be included in the sample group for the coloured progressive matrices test in the city of İzmir, schools were evaluated within the scope of stratified sampling according to the socio-economic levels as low, moderate and high. A total of 21 schools were then determined as 7 schools from each layer (low-moderate-high) by way of random assignment method. Since the norm values were divided into parts of six months in the original test, the sample group was similarly divided into groups of six months. It was determined that 39 children were between the ages of 3.9 and $4.2(4.2 \%), 131$ children between the ages of 4.3 and 4.8 (14.2\%), 218 children between the ages of 4.9 and $5.2(23.6 \%), 188$ children between the ages of 5.3 and $5.8(20.3 \%), 182$ children between the ages of 5.9 and $6.2(19.7 \%), 52$ children between the ages of 6.3 and $6.8(5.6 \%), 29$ children between 
the ages of 6.9 and 7.2 (\%3.1), 30 children between the ages of 7.3 and $7.8(3.2), 32$ children between the ages of 7.9 and 8.2 (3.5) and 24 children between the ages of 8.3 and $8.8(2.6 \%)$.

\subsection{Instrumentation}

The Coloured Progressive Matrices Test (CPM) which is mostly used for diagnosing the cognitive level during the pre-school period has been developed for evaluating mental development and intellectual maturity. The first standardization study for RPM was carried out by Raven in 1949 at the city of Dumfriesthis standardization put forth a value of .80 in test-re-test reliability. The classical form of the test was formed after this study. Whereas it was applied on 598 children during a follow-up norm study in 1982 (Raven et. al., 1998). Norm studies were also applied for RPM standardization in America, France, Canada, Italy, Hong Kong, India, Germany in addition to England (Cotton et. al., 2005).

Widespread use resulted in memorizing the test items thereby making it more difficult to control the evaluation. Test items were taught to the children for ensuring that they may be included in educational programs applied only for gifted children. That is why the Coloured Progressive Matrices Test was revised as a parallel form in 1998 in order to eliminate this problem (Raven et. al., 1998).

RPM that is revised and arranged as a parallel form is comprised of a total of 36 pieces with 3 sets of 12 each. These have been named as $\mathrm{A}, \mathrm{AB}$ and $\mathrm{B}$. The matrices have been designed to be used in anthropological and clinical studies applied on small children and the elderly. In addition, the test can also be applied on physically impaired, hearing impaired, those who cannot understand the spoken language and those who cannot speak (Raven et. al., 1998).

A total of 3 sets of 12 problems each modify the evaluation of the cognitive processes for children under the age of 11 for the coloured progressive matrices test. 3 sets provide 3 opportunities to the individual for developing consistent themes of thought and the whole test of 36 problems enables the evaluation of mental development and intellectual maturity. Book version of the test with colorful visuals or its presentation on the board with moving parts enables the problem to be perceived more clearly as well as its solution without the requirement for verbal explanation (Raven et. al., 1998).

RPM is quite easy to apply. Contrary to other tests, it does not have a strict style. RPM can easily be evaluated using answer sheets. A score of 1 is given for each correct answer. Correct answers are added up and the total scores are interpreted. The most satisfactory method while interpreting the total scores of the individual is comparison with the results of children in the same age group. Thus, it is possible to classify the individual with the obtained scores (Raven et. al., 1998).

Bender-Gestalt Visual Motor Perception Test (BG) Bender adopted these shapes in 1938 thus developing a test for measuring visual motor perception. It was at first used for mental damages and emotional problems (Palmer, 1983). However, BG test is now used for predicting visual motor development along with the related memory, time and space concept as well as organization ability. In this regard, BG Test can also be used as an intelligence test (Yalın \& Sonuvar, 1987).

The norm values of the BG Test on Turkish children have been obtained from 361 children living in an urban environment in addition to 129 children living in a rural environment (Yalın and Sonuvar, 1987). Another norm study was carried out by analyzing the values of 701 children living in Izmir. Test-re-test reliability values were determined as $0.80,0.73$ and 0.81 for $1^{\text {st }}, 2^{\text {nd }}$ and $3^{\text {rd }}$ grades respectively. The test results of $1^{\text {st }}$ grade students were scored by two different implementers and it was determined that the coefficient varied between .93 and .97 (Somer, 1988; Yalın \& Sonuvar 1987).

TONI-3, (Test of Nonverbal Intelligence-3) test has been developed by Brown, Sherbenou and Johnsen, (1997); it contains two parallel forms of A and B which can be applied to an age interval of 6-89, comprised of 45 items each of which can be scored dichotomically $(1,0)$. The TONI-3 test is advantageous for evaluating the general mental ability of individuals with linguistic, aural and motor skill problems (Korkmaz et. al., 2009).

An Adaptation study for the 6-11 age Turkish child sample group was carried out by Korkmaz et. al. (2009). The study was carried out during 2008-2010 at state schools with different socio-economic levels selected via stratified sampling. The sample group consisted of 318 female and 311 male students. Data were acquired from 10 groups separated into 6 month age intervals of $72-132$. KR-20 cofficient was determined to vary between 0.86 and 0.95 for the A form and between 0.90 and 0.93 for the B form between the months of 72-132 according to the internal reliability analyses of the TONI-3 test. A and B parallel form reliability coefficient for the whole sample group was determined as $r=0.80(n=486$, $\mathrm{p}<.01)$, test-re-test reliability coefficient applied with an interval of 30 days was determined as $r=0.63$ for $\mathrm{A}$ form and as $\mathrm{r}=0.72(\mathrm{n}=117, \mathrm{p}<.01)$ for $\mathrm{B}$ form. 


\subsection{Proceduers}

The Coloured Progressive Matrices Test and Toni-3 test were applied individually on the children in book format by the researcher at the Psychological Consultancy Department of schools. No time limitation was imposed. Whereas the Bender-Gestalt Visual Motor Perception Test was applied by the psychologist individually in accordance with the test directive.

\section{Results}

The Coloured Progressive Matrices Test reliability was analyzed using Kuder Richardson-20 (KR-20) and Spearman-Brown Formula by way of two split-half reliability and test-re-test reliability. K-20 provides internal consistency measurement for scales with binary coded variables (Anastasi \& Urbina, 1997; Portney \& Watkins, 2000). Since The Coloured Progressive Matrices Test is evaluated as an intelligence test, criterion-referenced validity analysis was used for examining the relationships with previously used intelligence tests. The relationship level between The Coloured Progressive Matrices Test and Bender-Gestalt Visual Motor Perception Test and TONI-3 tests was determined via Pearson Product-Moment formula for validity analyses. The age norms were then determined as percentile values according to age.

A significant differentiation according to gender is not expected in non-verbal cognitive tests independent of culture. To this end, it was analyzed in all age categories and groups via unrelated samples t-test whether the Coloured Progressive Matrices Test total scores differed with respect to gender or not. Two way variance analysis was carried out in order to determine whether Coloured Progressive Matrices Test total scores have a common effect on gender and age category levels or not and the age groups which differ among each other at a statistically significant level. Single factor variance analysis was applied to determine whether Coloured Progressive Matrices Test total scores differ according to age or not and Scheffe test was applied for determining the groups with the differences.

\subsection{The Reliability of CPM}

Analyses related with the internal consistency of the scale were carried out using the Coloured Progressive Matrices Test total scores. The Cronbach alpha coefficient for the whole scale was determined as 0.83. Whereas Spearman Brown two split-half correlation was determined as .80. RPM Test was applied to the sample group $(n=63)$ in four week intervals. A moderate, positive and statistically significant relationship was determined between the Coloured Progressive Matrices Test total test and Test-re-test results $(\mathrm{r}=0.611, \mathrm{p}<.01)$. Accordingly, it can be stated that the test is reliable upon examining the Cronbach alpha coefficient, Spearman Brown two split-half test correlation and Test-Re-Test results.

\subsection{The Validity of CPM}

The correlation values between the CPM test total scores applied to the sample group as part of the criterion-referenced validity analyzes and the Bender-Gestalt Visual Motor Perception Test and TONİ-3 test total scores have been calculated in Table 1.

Table 1. Correlation of the Coloured Progressive Test Scores with Bender and TONI-3 Tests

\begin{tabular}{lll}
\hline & $\begin{array}{l}\text { Bender } \\
(\mathbf{N}=\mathbf{7 5})\end{array}$ & $\begin{array}{l}\text { TONI-3 } \\
(\mathbf{N}=\mathbf{5 4})\end{array}$ \\
\hline $\mathbf{C P M}$ & $-0.703^{* *}$ & $0.643^{* *}$ \\
\hline
\end{tabular}

Bender test was applied on 75 children who were selected for the Coloured Progressive Matrices Test validity study by way of random sampling. A high, negative and statistically significant relationship is observed between the Coloured Progressive Matrices Test total test and Bender Test results $(\mathrm{r}=0.703, \mathrm{p}<.01)$. Children receive scores upon errors according to the Bender test directive. Whereas they are scored over correct items in the Coloured Progressive Matrices Test. Hence, these results indicate that the number of correct items in Coloured Progressive Matrices Test increases with decreasing error score in the Bender test.

Another non-verbal intelligence test TONI-3 test was applied for the Coloured Progressive Matrices Test validity study on 54 children selected via random assignment for correlation analysis. A moderate, positive and statistically significant relationship is observed between the results of Coloured Progressive Matrices Test and TONI-3 Test ( $\mathrm{r}=0.643, \mathrm{p}<.01)$. These results indicate a moderate relationship between TONI-3 test and Coloured Progressive Matrices Test. 


\subsection{Analysis by Gender}

Table 2. t-Test Results of Coloured Progressive Matrices Test According to Gender

\begin{tabular}{llllll}
\hline Gender & N & M & Sd & Df & T \\
\hline CPM Girl & 433 & 17.09 & 5.23 & \multirow{2}{*}{023} & 0.408 \\
CPM Boy & 492 & 17.24 & 5.64 & & 0.684 \\
\hline
\end{tabular}

Coloured Progressive Matrices Test Total Set scores do not put forth a statistically significant difference according to gender $[\mathrm{t}(923)=.408, \mathrm{p}>.01]$. This result can be interpreted as such that there is no statistically significant relationship between Coloured Progressive Matrices Test scores and gender.

The results of the Anova carried out for determining whether the Coloured Progressive Matrices Test scores of children differ according to the ages and gender of the children or not have been given in Table 3 .

Table 3. ANOVE Results for the Coloured Progressive Test Scores According to Gender and Age

\begin{tabular}{lllll}
\hline Source of the variance & Sum of squares & sd & Mean square & F \\
\hline Gender & 5.500 & 1 & 5.500 & .428 \\
Age & 15225.63 & 9 & 1691.738 & .513 \\
GenderXage & 177.571 & 9 & 19.739 & .000 \\
Error & 11.618 .99 & 905 & 12.839 & 1.53 \\
Total & 8102.775 & 925 & & 0.130 \\
\hline
\end{tabular}

The common effect of gender and age on the Coloured Progressive Matrices Test scores of children was not determined to be statistically significant $[F(1-925)=1.53 \mathrm{p}>.01]$. In other words, it is understood that the Coloured Progressive Matrices Test scores vary according to age and that the scores of girls and boys do not differ. This result indicates that there is no interaction between age groups and gender.

3.4 Analysis by Age

Table 4. ANOVE Results for the Coloured Progressive Test Scores According to Age

\begin{tabular}{lllllll}
\hline & Source of variance & Sum of Squares & sd & Mean Square & F & p \\
\hline \multirow{3}{*}{ CPM } & Between Groups & 15697.87 & 9 & 1744.20 & $135.28,000$ \\
& Whithin Groups & 11797.04 & 915 & 12.89 & & \\
& Total & 27494.92 & 924 & & &
\end{tabular}

According to the analysis results that there is a statistically significant difference between the set total scores according to age $[F(9-915)=135,28 p<.01]$. In other words, Coloured Progressive Matrices Test scores vary at a statistically significant level depending on the ages of the children. According to the Scheffe test results carried out for determining the groups with age differences; it was determined that older age groups have higher score averages in comparison with lower age group children.

\subsection{Percentile Ranks}

The percentile values of the children in the sample group have been given in Table 5. Percentile values have been given only for the pre-school period since the objective is to make a contribution to the diagnosis of children in the pre-school period and since the number of children in the older age groups is lower than those in these groups.

Table 5. Percentile scores for each age level

\begin{tabular}{llllll}
\hline Percentile & Age & & & & \\
\hline & $\mathbf{3 . 9 - 4 . 2}$ & $\mathbf{4 . 3 - 4 . 8}$ & $\mathbf{4 . 9 - 5 . 2}$ & $\mathbf{5 . 3 - 5 . 8}$ & $\mathbf{5 . 9 - 6 . 2}$ \\
\hline $\mathbf{9 5}$ & 17 & 20 & 21 & 23 & 24 \\
$\mathbf{9 0}$ & 16 & 18 & 19 & 21 & 23 \\
$\mathbf{7 5}$ & 14 & 16 & 17 & 18 & 20 \\
$\mathbf{5 0}$ & 13 & 14 & 15 & 16 & 17 \\
$\mathbf{2 5}$ & 11 & 12 & 13 & 13 & 15 \\
$\mathbf{1 0}$ & 11 & 11 & 11 & 12 & 13 \\
$\mathbf{5}$ & 10 & 10 & 10 & 11 & 12 \\
\hline
\end{tabular}

\section{Discussion}

Validity and reliability examinations were carried out within the scope of this study for the CPM test 3-9 age interval children sample group with an objective of generating norms for the aforementioned age interval. Results acquired from the study provided psychometric data indicating that the CPM test would be compatible for the use of researchers. 
Consistency coefficient between the scores of CPM applied at different times was examined by way of test-re-test method. The correlations that CPM puts forth with re-tests carried out on a sample group of 63 people with four week intervals (30 days) indicate that it is perpetual and stable during the time that passed. As put forth by Raven et. al. in (1998), reliability coefficient was determined as .85 as a result of the re-test carried out 1 month later in Slovakia during studies on age groups between 4 and 11 . Values decreased slightly in longer times. For instance, the result of the test that was repeated 1 year later in Singapore was reported as .71, whereas the result of the re-test applied 6 months later in Nigeria was reported as .59. The re-test reliability coefficient was determined as .55 during the study carried out by Bildiren, Kargin and Korkmaz (2017) on children between the ages of 4-6. The test-re-test results obtained in this study were in accordance with these results.

The internal consistency-reliability coefficients of CPM and Spearman Brown split-half test correlation were determined. When the acquired results were evaluated, it was observed that the internal consistency coefficient $(r=.83)$ and Spearman Brown split-half test correlation $(\mathrm{r}=.80)$ were high which indicates that CPM can be used on individuals between the age interval of 3-9 in a reliable manner. These results were in accordance with those of previous studies (Muller, 1970; Reddington \& Jackson; 1981; Simoes, 1989; Cotton et. al., 2005). Psychometrists put forth that reliability coefficients of above 0.85 for standardized intelligence tests can be interpreted as indicating that measurement errors have almost no effect (Murphy \& Davidshofer, 2005). Therefore, it can be stated that CPM yields reliable results.

It was determined that CPM scores had high level of correlation with Bender (.703) and moderate level of correlation with Toni-3 (.643) within the scope of convergent validity. The fact that CPM test scores correlate with Bender test and Toni-3 test when these results are taken into consideration are among the expectations from the study in relation with same measurements. These results are also quite meaningful as typical indicators of abstract reasoning, judgment, problem solving general skill levels. CPM and Terman-Merrill and Goodenough tests were compared for the test applied on Spanish speaking children as a result of which a high level of correlation was determined between them. This correlation was .94 for children with disabilities and .59 for normal children. Whereas the correlations with Goodenough test were .76 and .66 (Raven et. al., 1998). It can be stated according to these findings that the Coloured Progressive Matrices Test is a valid test for the studied sample group.

No statistically significant differentiation was determined in the CPM test scores with respect to gender. It was determined that the gender variable did not have a main impact as a result of the two-way variance analyses carried out between gender, age level and RPM test total test scores, whereas it was determined that the age variable has a main impact and that there was no interaction between gender and age. This is a more expected result theoretically; it indicates that the mean CPM scores are not roughly biased according to gender. In addition, the acquired results are also in accordance with the results of the England norm samples of CPM (Raven et. al., 1998) as well as the findings from the Australia norm samples.

It was determined as a result of examining the differentiation of CPM according to age groups that an increase in age also increases general talent intelligence level mean scores. This supports the idea expressed mostly by intelligence theorists that cognitive performance develops proportionally with age until the end of adolescence (Santrock, 2012).

When evaluating the general results of this research study, it can be stated that CPM test is a valid and reliable tool of measurement for measuring general skill and mental capacity. CPM can be used especially if it is required to acquire a general information on the general mental capacities of individuals during the diagnostic decision making process. It is considered that it will make a significant contribution to the objective evaluation of gifted children during the pre-school period. However, even though these tests provide an intelligence score interval just like Wechsler or similar intelligence tests, this cannot be thought of as a completely clinical diagnostic tool. Because, they provide general skill measurement based only on performance. However, the verbal general skill levels of the individuals are also very important during the diagnosis process. Hence, standardized verbal intelligence tests should also be used when carrying out the general mental capacity measurements of individuals in addition to CPM.

In this study, the sample group was determined by taking into account the socio-economic layer. However, the fact that the study has been carried out only in the city of İzmir limits the generalization of the acquired results. Socioeconomic structure in Turkey varies according to geographic regions. Even though it is claimed that CPM is a test that is independent of culture, it is suggested to examine the test with a larger sample group.

\section{References}

Akarsu, F. (2001). Üstün yetenekli çocuklar aileleri ve sorunları, Ankara: Eduser Yayınları.

Anastasi, A., \& Urbina, S. (1997). Psychological testing. New Jersey: Prentice-Hall.

Bildiren, A., Kargın, T., \& Korkmaz, M. (2017). Reliability and Validity of Colored Progressive Matrices for 4-6 Age Children. Türk Üstün Zekâ ve Egitim Dergisi, 7(1), 19. 
Burns, J. M., \& Tunnard, J. D. (1991). Public programming for precocious preschoolers. Gifted Child Today, 14(6), 5660. https://doi.org/10.1177/107621759101400623

Burns, J. M., Matthews, F. N., \& Mason, A. (1990). Essential steps in screening and identifying preschool gifted children. Gifted Child Quarterly, 34(3), 102-107. https://doi.org/10.1177/001698629003400303

Burns, T. G., \& O’Leary, S. D. (2004). Wechsler Intelligence Scale for Children-IV: Test review. Applied Neuropsychology, 11(4), 233-236. https://doi.org/10.1207/s15324826an1104_11

Castellano, J. A. (2002). Renavigating the waters: The identification and assessment of culturally and linguistically diverse students for gifted and talented education. In J. A. Castellano, \& E. I. Diaz (Eds.), Reaching new horizons: Gifted and Talented Education for Culturally and Linguistically Diverse Students (pp. 94-116). Boston, MA: Allyn and Bacon.

Cotton, S. M., Kiely, M. P., Crewther, D. P., Thomson, B., Laycock, R., \& Crewther, S. G. (2005). A normative and reliability study for the Raven's Coloured Progressive Matrices for primary school aged children from Victoria. Australia Personality and Individual Differences, 39, 647-659. https://doi.org/10.1016/j.paid.2005.02.015

Johnsen, S. (2009). Best practices for identifying gifted students. Principal, 88, 8-14.

Karnes, F. A., Shaunessy, E., \& Bisland, A. (2004). Gifted students with disabilities: Are we finding them? Gifted Child Today, 27(4), 16-21. https://doi.org/10.4219/gct-2004-148

Kirschenbaum, R. (1998). Dynamic assessment and its use with underserved gifted and talented populations. Gifted Child Quarterly, 42(3), 140-147. https://doi.org/10.1177/001698629804200302

Korkmaz, M., Demiral, N., Dural, S., Güngör, D., Bildiren, A., \& Erdik, E. (2012). Toni 3- sözel olmayan zeka testinin 6-11 yaş örneklemi geçerlik ve güvenilir çalışması. Ege Üniversitesi Bilimsel Araştırma Projesi.

Lewis, J., DeCamp-Fritson, S., Ramage, J., McFarland, M., \& Archwamety, T. (2007). Selecting for ethnically diverse children who may be gifted using Raven's Standard Progressive Matrices and Naglieri Nonverbal Abilities Test. Multicultural Education, 15, 38-42.

Lohman, D., Korb, K., \& Lakin, J. (2008). Identifying academically gifted English-language learners using nonverbal tests: A comparison of the Raven, NNAT, and CogAT. Gifted Child Quarterly, 52, 275-296. https://doi.org/10.1177/0016986208321808

Louis, B., Lewis, M., \& Feiring, C. (1991). Identification of minority inner-city gifted preschool children. Paper presented at the ACYF Research Conference, Crystal City, VA.

Moon, S. M., \& Rosselli, H. C. (2000). Developing Gifted Programs. In K.A. Heller, F.J. https://doi.org/10.1016/B978-008043796-5/50035-8

Muller, R. (1970). Eline kritische empirische Untersuchung des Draw-a-Man Test und der Coloured Progressive Matrices. Diagnostica, 16, 138-147.

Murphy, K. R., \& Davidshofer, C. O. (2005). Psychological testing: Principles and applications. Sixth Edition, Pearson Education, Inc., New Jersey.

Naglieri, J. A., \& Ford, D. Y. (2005). Increasing minority children's participation in gifted classes using the NNAT: A response to Lohman. Gifted Child Quarterly, 49, 29-36. https://doi.org/10.1177/001698620504900104

National Association for Gifted Children [NAGC] \& Council for Exceptional Children [CEC]. (2006). National Association for Gifted Children [NAGC] \& Council for Exceptional Children [CEC]. (2006). NAGC-CEC Teacher knowledge \& skill standards for gifted and talented education. Retrieved from www.nagc.org/...standards/ final\%20standards\%20(2006).pdf.

Öner, N. (1997). Türkiye’de Kullanılan Psikolojik Testler. İstanbul: Boğaziçi Üniversitesi Yayınları.

Özgüven, İ. E. (2007). Psikolojik Testler. Ankara: Pdrem Yayınları.

Palmer J. O. (1983). The psychological assesment of children. New York, John Wiley and Sons Inc, 200.

Parkinson, M. L. (1990). Finding and serving gifted preschoolers. Understanding Our Gifted, 2(5), 1-13.

Pfeiffer, S. I. (2002). Identifying gifted and talented students: Recurring issues and promising solutions. Journal of Applied School Psychology, 19(1), 31-50.

Pfeiffer, S. I., \& Jarosewich, T. (2003). The Gifted rating scales. San Antonio, TX: Psychological Corporation.

Pfeiffer, S. I., \& Petscher, Y. (2008). Identifying young gifted children using the gifted rating scalespreschool/kindergarten form. Gifted Child Quarterly, 52(1), 19-29. https://doi.org/10.1177/0016986207311055 
Portney, L. G., \& Watkins, M. P. (2000). Foundations of Clinical Research. Applications to Practice (2nd ed.). New Jersey: Prentice Hall Health.

Raven, J., Raven, J. C., \& Court, H. (1998). Coloured Progressive Matrices. 1998 Edition. USA: Harcourt Assesment.

Reddington, M. J., \& Jackson, K. (1981). The Raven_s Coloured Progressive Matrices (1956): A Queensland standardization. Australian Council for Educational Research Bulletin for Psychologists, 30, 20-26.

Robinson, N. M., \& Weimert, L. J. (1990). Selection of candidates for early admission to kindergarten and first grade. In W. T. Southern \& E. D. Jones (Eds.), The academic acceleration of gifted children (pp. 29-50). New York, NY: Teachers College Press.

Rogers, M. T., \& Silverman, L. (1988). Recognizing giftedness in young children. Understanding Our Gifted, 1(2), 520.

Sandall, S., Hemmeter, M. L., Smith, B. J., \& McLean, M. E. (2005). The division for early childhood [DEC]-Recommended practices: A comprehensive guide for practical application in early intervention/early childhood special education. Longmont, CO: Sopris West.

Sankar-DeLeeuw, N. (2002). Gifted preschoolers: Parent and teacher views on identification, early admission, and programming. Roeper Review, 24(3), 172-177. https://doi.org/10.1080/02783190209554174

Santrock, J. W. (2012). Ergenlik. Nobel Akademik Yayınc1l1k.

Sattler, J. M. (2001). Assessment of children: Cognitive applications. San Diego, CA: Jerome M. Sattler.

Shaklee, B., \& Hansford, S. (1992). Identification of underserved populations: Focus on preschool and primary children. OH: Columbus, Ohio State Department of Education.

Silverman, L. (2009). What we have learned about gifted children. Retrieved january 26, from www.gifteddevelopment.com/What_is_Gifted/learned.htm .

Simoes, M. M. R. (1989). Um Estudo Exploratorio comp o Teste das Matrices Progressivas de Raven Para Criancas (CPM/PM47). Paper presented at the "Psychology and Psychologists Today Congress", Lisbon.

Somer, O. (1988). Çocuklar için gelişimsel bender gestalt görsel motor algllama testi üzerine bir çalışma (izmir şehir örnekleminde norm, geçerlik ve güvenirlik çalışması). (Unpublished master's thesis). Ege Üniversity, İzmir.

Yalın, A., \& Sonuvar, B. (1987). Beş Farklı Organik Grupta Bender Gestalt Testinin Uygulanması. Psikoloji Dergisi, 21, 83-85.

\section{Copyrights}

Copyright for this article is retained by the author(s), with first publication rights granted to the journal.

This is an open-access article distributed under the terms and conditions of the Creative Commons Attribution license which permits unrestricted use, distribution, and reproduction in any medium, provided the original work is properly cited. 